\title{
LAS MUJERES, LAS GUERRAS Y EL DERECHO INTERNACIONAL HUMANITARIO ${ }^{1}$
}

\author{
Marta Postigo Asenjo \\ martapostigo@uma.es \\ Universidad de Málaga
}

Recibido: 28-02-2011

Aceptado: 29-03-2011

\section{Resumen}

La violencia sexual se emplea como instrumento de intimidación, castigo y terror, e incluso coadyuvante de limpieza étnica, en los conflictos armados. En las últimas décadas, se han producido importantes avances en la inclusión de la violación entre los crímenes contra el derecho internacional humanitario. Sin embargo, aún son necesarias acciones más eficaces para evitar que se produzcan violaciones sistemáticas en las zonas en conflictos y post-conflicto. Este trabajo destaca la importancia que tiene la lucha por la igualdad y la incorporación de las mujeres en los procesos de toma de decisiones para combatir esta lacra y asegurar la paz y la estabilidad.

Palabras clave: Violencia sexual, derecho internacional humanitario, conflicto armado, paz, mujeres, igualdad.

\begin{abstract}
Sexual violence has long been used as a weapon of war, with the purpose of intimidating, injuring and punishing civilians, and even as an ethnic cleansing adjuvant, in armed conflicts. In the last decades, though, there have been important advances towards the definition and prosecution of rape as a crime against international humanitarian law. Notwithstanding, more effective measures are needed to protect women from this heinous crime in the conflict zones and post-conflict. This article stresses the need to keep struggling for gender equality and improving women's participation in decision making processes to achieve peace and stability.
\end{abstract}

Keywords: Sexual violence, international humanitarian law, armed conflict, peace, women, equality.

\footnotetext{
${ }^{1}$ Este trabajo forma parte de los resultados de investigación del proyecto "Las retóricas de la democracia", VI Plan Nacional de I+D+i, código FFI2008-00039.
} 


\section{Introducción}

La violencia sexual en las guerras no es un fenómeno nuevo. Se trata lamentablemente de una agresión que afecta a mujeres y niñas en los conflictos armados que, sin embargo, no ha recibido una respuesta eficaz por parte de la comunidad internacional y su tratamiento en el derecho internacional humanitario es reciente ${ }^{2}$.

En este trabajo se analiza el impacto que la perspectiva de género ha tenido y tiene en el derecho internacional humanitario $y$ de los derechos humanos, particularmente, en la definición de la violencia sexual en los conflictos armados -las violaciones, los embarazos forzados y la prostitución forzada- como crimen de guerra y contra la humanidad.

El texto concluye que, a pesar de los avances que se han producido en los últimos años, tanto los Estados como la comunidad internacional han de tomar medidas jurídicas, sociales y de seguridad más eficaces para evitar que las agresiones sexuales y las violaciones sean empleadas sistemáticamente como instrumentos de intimidación, coacción y limpieza étnica contra la población civil en los conflictos contemporáneos y que queden impunes.

Asimismo, se pone de relieve la importancia que tiene la participación femenina en los procesos de toma de decisiones y de negociación para la paz, entendiendo que la lucha contra la violencia sexual en los conflictos armados es parte del avance general en la condición jurídica y social de las mujeres.

\section{La visibilidad de las mujeres: la paz y la guerra}

La flagrante violación de los derechos humanos de las mujeres en los conflictos armados y el uso de la violencia sexual como forma de intimidación, terror y limpieza étnica, no son lamentablemente hechos aislados. Los conflictos étnicos que han tenido lugar en el corazón de Europa y en África en la última década del siglo XX, son un claro reflejo de que esta brutalidad no es cosa del pasado.

Sin embargo, resulta paradójico que las violaciones sistemáticas de mujeres y niñas en las guerras, hayan recibido tan sólo una respuesta vaga por parte de la

\footnotetext{
${ }^{2}$ Véase a este respecto el trabajo de Melissa Goldenberg Goldstoff (2010: 491).
} 
comunidad internacional. Esta falta de atención responde a un desinterés histórico más general hacia las circunstancias de las ciudadanas y sus derechos en el seno de la ciudadanía y la sociedad. Por fortuna, la inclusión de la perspectiva de género en las distintas disciplinas académicas, así como en el ámbito jurídico y político, está permitiendo que, en las últimas décadas del siglo $\mathrm{XX}$, se estén produciendo avances en la condición jurídica y cívica de las mujeres.

Como es sabido, las dos Guerras Mundiales supusieron un cambio profundo en el papel social y en el estatus político de las ciudadanas. Tras la Primera Guerra Mundial, las mujeres obtuvieron su merecido derecho al voto en la mayoría de los países democráticos. Ciertamente, al terminar las guerras mundiales, la mayoría volvieron a sus hogares a ocuparse de las actividades domésticas y reproductivas. Sin embargo, su contribución al mantenimiento de la sociedad y de la economía mientras los hombres habían permanecido ausentes, puso en evidencia a quienes habían negado públicamente la capacidad de éstas para participar en la esfera pública y productiva ${ }^{3}$. Las puertas de la ciudadanía se habrían a las ciudadanas, y desde entonces, se hizo más difícil justificar su exclusión de la esfera económica y pública ${ }^{4}$.

Ahora bien, la documentación y la información sobre el papel de las mujeres en las guerras ha sido escasa y ello ha contribuido a que su aportación haya pasado desapercibida y a que las violaciones de sus derechos fundamentales hayan quedado impunes.

En las últimas décadas del siglo XX, se han producido avances en la posición cívica y jurídica de las mujeres, y se están superando viejos prejuicios y discriminaciones formales basadas en el sexo. A estos cambios no permanecen ajenas las fuerzas armadas y de seguridad, tanto nacionales como internacionales ${ }^{5}$. Las mujeres juegan un papel cada vez más activo en las acciones e intervenciones

\footnotetext{
${ }^{3}$ Sobre los controvertidos debates que tuvieron lugar en el Reino Unido en la segunda mitad del siglo XIX, en torno a los movimientos sufragistas y el derecho al voto de las ciudadanas, véase Paula Bartley (2003).

${ }^{4}$ Ciertamente, tal y como puso de relieve Betty Friedan en su obra decisiva para el despertar del feminismo de su letargo tras la Segunda Guerra Mundial, los discursos públicos promovieron durante la década de los cincuenta del siglo XX una nueva "mística de la feminidad" que supuso un estancamiento en las oportunidades y los papeles sociales de las ciudadanas en los países democráticos y libres. En consecuencia, el feminismo tuvo que reaparecer en la esfera pública a mediados de los sesenta y setenta del siglo XX, para impulsar el avance hacia la igualdad real entre los sexos. Véase Betty Friedan (1992), $1^{\text {a }}$ edición en 1963.

${ }^{5}$ Véanse los datos de la participación femenina en los principales ejércitos y el análisis de Katrin Bennhold (2010) y Doreen Carvajal (2010).
} 
militares y humanitarias, y lamentablemente también en los atentados terroristas y los grupos armados ${ }^{6}$.

Algunos estudios defienden que es erróneo atribuir una especial vulnerabilidad al sexo femenino en los conflictos ${ }^{7}$. Sin embargo, los informes más recientes de las Naciones Unidas insisten en que la población civil es cada vez más vulnerable en las guerras contemporáneas, que suelen ser internas y de carácter étnico. De acuerdo con el Fondo de las Naciones Unidas para las Mujeres, casi el 90 por ciento de las víctimas de las guerras contemporáneas se encuentran entre la población civil, en su mayoría, mujeres y niños ${ }^{8}$.

No conviene ignorar que aunque el sufrimiento y las consecuencias de las guerras las padecen dramáticamente tanto hombres como mujeres, existen diferencias de género que deben ser tenidas en cuenta por los gobiernos y la comunidad internacional.

Las violaciones de los derechos humanos de las mujeres en los conflictos armados han quedado frecuentemente impunes. Sin embargo, en las últimas décadas se han producido avances significativos en el reconocimiento de los efectos que las guerras producen en las mujeres, así como en el reconocimiento de que cada violación es un crimen contra el derecho internacional humanitario que ampara a las personas en situaciones de conflicto armado.

Estos avances no hubieran sido posibles sin los esfuerzos y presión de los movimientos feministas, que han promovido un cambio de perspectiva en la comunidad internacional. En 1972, las Naciones Unidas declaraban 1975 el “Año Internacional de la Mujer" para avanzar en la igualdad entre los sexos, integrar la perspectiva de género en el desarrollo, e impulsar la participación femenina en la toma decisiones y los procesos de paz ${ }^{9}$.

\footnotetext{
${ }^{6}$ Véase Charlotte Lindsey (2000: 561-580).

${ }^{7}$ De acuerdo con el Comité Internacional de la Cruz Roja (CICR, 2007), los hombres representan el 96 por ciento de los detenidos y el 90 por ciento de las personas desparecidas en los conflictos. En tanto que se encuentran entre la mayoría de los reclutados por los grupos y fuerzas armadas, éstos están expuestos a ser heridos o asesinados como objetivos legítimos de ataques, y en su calidad de opositores militares reales o potenciales, suelen ser objetivo de los opositores políticos, víctimas de privación de libertad y de ejecuciones sumarias.

${ }^{8}$ Fondo de las Naciones Unidas para las Mujeres (UNIFEM, 2011). Véanse asimismo la Resolución 1820 de 2008 del Consejo de seguridad de las Naciones Unidas (Consejo de Seguridad de las Naciones Unidas, 2008); Resolución 1325 de 2000 (Consejo de Seguridad de las Naciones Unidas, 2000) y Lindsey (2000).

${ }^{9}$ Véase el "Report of the world conference to review and appraise the achievements of the United Nations decade for women: Equality development and peace" (Naciones Unidas, 1985: 9).
} 
Las cuatro Conferencias Mundiales sobre la Mujer que han tenido lugar bajo el paraguas de la Década de las Naciones Unidas para la Mujer sobre "Igualdad, desarrollo y paz" (1975-1985), han supuesto un paso decisivo en el compromiso internacional para avanzar en la condición social y jurídica de las mujeres ${ }^{10}$. En dichas conferencias, que han reunido a miembros de la sociedad civil de todas las regiones, se ha preparado el guión de la acción internacional y de los estados para avanzar en los derechos y oportunidades de las ciudadanas.

La Década de las Naciones Unidas sobre la Mujer (1975-1985) ha supuesto, asimismo el reconocimiento internacional del papel que tienen las mujeres en los procesos de paz. Por ello, una idea central común a las decisiones tomadas en las cuatro conferencias mundiales, es que la participación de las mujeres en los procesos de toma de decisiones, a nivel local, nacional e internacional, constituye un aspecto clave para avanzar en el desarrollo humano y para mantener la paz y la estabilidad de las regiones y naciones. "La paz está indisociablemente ligada a la igualdad entre las mujeres y los hombres y al desarrollo", declaraba la Plataforma de Acción de la Cuarta Conferencia Mundial sobre la Mujer ${ }^{11}$.

En 1979, la Asamblea General de las Naciones Unidas aprobaba la Convención sobre la eliminación de todas las formas de discriminación contra las mujeres (CEDAW), que constituye el instrumento normativo básico en la lucha internacional por la igualdad y contra la discriminación por razón de sexo ${ }^{12}$. Sin embargo, hubo que

\footnotetext{
${ }^{10}$ La primera conferencia mundial sobre la mujer fue organizada por las Naciones Unidas en 1975, el Año Internacional de la Mujer, en la Ciudad de México. La segunda conferencia mundial sobre la mujer tuvo lugar en Copenhague, en 1980; la tercera, en Nairobi, en 1985; y la cuarta, en Beijing, en 1995. La Declaración y la Plataforma de Acción de Beijing sirven, actualmente, como guías de actuación para avanzar en los derechos y condiciones de vida de las ciudadanas en todas las regiones. Véanse "Fourth World Conference on Women. Platform for action" en WomenWatch (Naciones Unidas, 1995) y "Las cuatro conferencias mundiales sobre la mujer, 1975-1995. Una perspectiva histórica" (Naciones Unidas: 2000).

${ }^{11}$ Women and Armed Conflict (Naciones Unidas, 1995).

${ }^{12}$ Adoptada y abierta a firma y ratificación, o adhesión, por la Asamblea General de las Naciones Unidas, en su resolución 34/180, de 18 de diciembre de 1979, entrada en vigor el 3 de septiembre de 1981. Se trata del único tratado de los derechos humanos que reafirma los derechos reproductivos de las mujeres, aborda la influencia de las tradiciones culturales en el mantenimiento de prácticas discriminatorias y define expresamente la discriminación por razón de sexo de forma amplia y sustancial. Asimismo, la Convención tiene fuerza vinculante para los Estados que la han ratificado, que están obligados a remitir informes periódicos a las Naciones Unidas para mostrar su grado de cumplimiento. Como toda Convención y Tratado sobre derechos humanos, ésta se enfrenta aún a importante retos para alcanzar su plena eficacia y cumplimiento por parte de los Estados que la han ratificado, y, claro está, para lograr la ratificación y adhesión de aquellos Estados que aún no lo han hecho. Puede consultarse la Convención en español, junto a su situación de ratificación, reservas y declaraciones, en la página web oficial de la Oficina del Alto Comisionado de las Naciones Unidas para los Derechos Humanos (OACDH, 1979).
} 
esperar hasta 1993 para que las Naciones Unidas dictaran la Declaración sobre la eliminación de la violencia contra la mujer ${ }^{13}$, ofreciendo, por primera vez, una definición precisa y amplia de la violencia de género, e incluyendo las recomendaciones y las pautas a seguir por los estados para hacer frente a esta lacra global.

Estos instrumentos legales constituyen un claro reflejo de que los asuntos y los derechos de las mujeres se han situado en la agenda pública internacional. Aunque los cambios en las relaciones de género son lentos, especialmente en las regiones en las que, junto a los roles tradicionales y las costumbres patriarcales, existen conflictos armados y guerras, la presión de los organismos internacionales y de las asociaciones y organizaciones no gubernamentales van dando poco a poco sus frutos.

Un resultado relevante es el reconocimiento de la contribución de las mujeres en el mantenimiento de la paz y la estabilidad, así como la definición de la violencia sexual como crimen contra la humanidad y de guerra que, como muestra el siguiente apartado, ha sido un recorrido lento y difícil, y todavía queda un largo camino por andar para que las mujeres estén eficazmente protegidas contra la violencia sexual en los conflictos $\operatorname{armados}^{14}$.

\section{Las violaciones y la violencia sexual como crímenes contra el derecho internacional humanitario: un largo recorrido}

En el año 2008, la entonces Secretaria de Estado de Estados Unidos, Condoleezza Rice, cuestionaba ante el Consejo de Seguridad de las Naciones Unidas que la violencia sexual y las violaciones en las guerras y conflictos armados sean amenazas para la seguridad y la paz, y en consecuencia, un asunto que compete al Consejo de Seguridad de las Naciones Unidas. "Afirmamos", dijo tras plantear la cuestión, "que la violencia sexual afecta profundamente no sólo a la salud y seguridad de las mujeres, sino a la estabilidad social y económica de sus naciones"15.

\footnotetext{
${ }^{13}$ Resolución 48/104 de la Asamblea General de las Naciones Unidas, de 20 de diciembre de 1993 (Naciones Unidas, 1993).

${ }^{14}$ En Liberia, tras 14 años de guerra civil, se ha situado a las mujeres en el centro de la reconstrucción y la pacificación. Para ello se ha elegido a una mujer presidenta, Ellen Johnson Sirleaf, y se han creado cuerpos policiales y de seguridad femeninos.

${ }^{15}$ Palabras pronunciadas por Condoleezza Rice ante el Consejo de Seguridad de las Naciones Unidas, en la sesión 5916 de 19 de junio de 2008 (Consejo de Seguridad de las Naciones Unidas, 2008).
} 
A pesar de que, lamentablemente, se trata de una práctica frecuente en las guerras y conflictos armados, la violencia sexual ha sido tratada como un tabú por las autoridades, que no se han atrevido a actuar, y ha recibido un tratamiento débil e ineficaz por parte de la justicia internacional (Henckaerts, Jean-Marie, 2008).

Tras la Segunda Guerra Mundial, los estatutos de los Tribunales de Núremberg y de Tokio, precedentes de la justicia internacional y del derecho internacional humanitario, no incluyeron la violación como crimen de guerra. El Tribunal de Núremberg no enjuició ni condenó las violaciones y la violencia sexual cometidas por los criminales nazis, y aunque el Tribunal de Tokio dictó la primera condena por violación en un tribunal militar, dicho delito no había sido tipificado como un crimen de guerra y contra la humanidad en sí mismo, sino como parte de otros delitos y ofensas graves en la guerra ${ }^{16}$.

Ciertamente, siguiendo la tradición del derecho internacional consuetudinario $^{17}$, las cuatro Convenciones de Ginebra del 12 de agosto de 1949, para la protección de las víctimas de guerra, y sus dos Protocolos adicionales, del 8 de junio de 1977, prohíben expresamente la violencia sexual y la violación por parte de los $\operatorname{soldados}^{18}$. El artículo 27, apartado 2, del Cuarto Convenio de Ginebra sobre la protección a la población civil en la guerra, establece que las mujeres deben ser especialmente protegidas "contra todo ataque a su honor y, en particular, contra la violencia sexual, la prostitución forzada y todo asalto al pudor"19. Junto a ello, el

\footnotetext{
${ }^{16}$ En palabras de Goldenberg Goldstof (2010: 497): "Los redactores y fiscales de los Tribunales Penales Internacionales tenían la capacidad de perseguir y condenar los crímenes sexuales cometidos durante la Segunda Guerra Mundial. Su rechazo a hacerlo sugiere una falta de atención e indiferencia hacia los crímenes sexuales como la violación, a pesar del estatus que dichos crímenes tenían bajo el derecho internacional consuetudinario".

${ }^{17}$ Véanse las Conferencias de Paz de la Haya de 1899 (IHL, 1899 y 1899a), la Cuarta Convención de la Haya, "Respetando las leyes y costumbres de guerra terrestre y sus anexiones", aprobada el 18 de octubre de 1907 (IHL, 1907), en vigor el 26 de enero de 1910. El artículo 46 de dicha Convención estipula que el "honor de la familia y los derechos, las vidas de las personas y la propiedad privada, así como las convicciones y prácticas religiosas, deben ser respetadas. La propiedad privada no puede ser confiscada". Se trata, como vemos, de una protección del honor familiar.

${ }^{18}$ Las Cuatro Convenciones de Ginebra, junto a sus Protocolos adicionales, pueden consultarse en la página web oficial del Comité Internacional de la Cruz Roja (Geneva Conventions, 2008).

${ }^{19}$ Convention (IV) relative to the protection of civilian persons in times of war, Ginebra, 12 de agosto de 1949 (IHL, 1949a). Junto a ello, el artículo 76 del Protocolo adicional I, estipula que las mujeres "serán objeto de un respeto especial y protegidas en particular contra la violación, la prostitución forzada y cualquier otra forma de atentado al pudor", y el artículo 14, apartado 2, del Tercer Convenio de Ginebra relativo al trato debido a los prisioneros de guerra, así como el artículo 75 del Protocolo adicional I, contemplan el factor del sexo, y en virtud de ello establecen que las mujeres deben ser tratadas con todas las consideraciones debidas a su sexo si son prisioneras (IHL, 1949).
} 
artículo 3 común a los cuatro Convenios y el Protocolo adicional I, prohíben los atentados contra la dignidad personal, en especial los tratos humillantes y degradantes, y la prostitución forzada ${ }^{20}$.

Sin embargo, estas provisiones no han estado exentas de polémica. La protección especial que recibe el honor de las mujeres en el derecho internacional humanitario -artículo 27 del Cuarto Convenio de Ginebra- ha suscitado críticas por quienes consideran que las violaciones sexuales no atentan contra el honor de las mujeres, sino contra su integridad física y sexual, su dignidad y sus derechos humanos (Lindsey, 2000). Como resultado de ello, se ha producido un cambio en el lenguaje jurídico que hace referencia a este tipo de delitos y el artículo 76 del Protocolo adicional I contiene ya una redacción distinta.

A pesar de que las Convenciones de Ginebra otorgan protección a las mujeres en la guerra como miembros de la población civil y también como combatientes, éstas no incluyeron la violencia sexual entre las "infracciones graves" a ser criminalizadas y condenadas (Goldenberg Goldstof, 2010: 498). Por otra parte, éstas han mostrado su ineficacia si tenemos en cuenta que, en la última década del siglo XX, han tenido lugar conflictos étnicos en el corazón de Europa -en los Balcanes entre 1991 y 1995- y en África, que han puesto de relieve la dimensión brutal con que se emplea la violencia sexual como instrumento de intimidación y limpieza étnica, también en los conflictos contemporáneos.

En Ruanda, se estima que entre 150.000 y 250.000 mujeres fueron violadas en el exterminio genocida contra la minoría tutsi que tuvo lugar 1994, muchas de las cuales fueron contagiadas del virus VHI, han tenido embarazos no deseados, y las que han sobrevivido padecen graves daños físicos y psicológicos ${ }^{21}$.

En el año 1994, basándose en los informes del Relator Especial de los Derechos Humanos sobre la situación de las mujeres en la ex Yugoslavia, la Comisión de Derechos de las Naciones Unidas emitía un informe, que se convertía en una Resolución de la Asamblea General de las Naciones Unidas en 1996, de condena hacia la violencia sexual de las mujeres en la guerra de los Balcanes, exigiendo a la

\footnotetext{
${ }^{20}$ Convention (IV) relative to the protection of civilian persons in times of war, artículo 3 (IHL, 1949a).

${ }^{21}$ Conviene tener en cuenta que las cifras indican el número estimado de mujeres violadas durante el conflicto, pero no aquellas que han pacido la violencia sexual posteriormente. Véase el portal electrónico de las Naciones Unidas dedicado al genocidio en Ruanda (Enseñanzas extraídas de Rwanda, 2011).
} 
comunidad internacional y a las partes implicadas poner fin a este tipo de crímenes y que se juzguen a los autores de delitos contra el derecho internacional humanitarios ${ }^{22}$.

Estableciendo precedentes significativos para la justicia internacional, el Consejo de Seguridad de las Naciones Unidas había aprobado en 1993 y 1994, dos resoluciones por las que se instituían los Tribunales Penales Internacionales ad hoc para juzgar los crímenes contra el derecho internacional humanitario cometidos en el territorio de la ex Yugoslavia y en Ruanda, respectivamente ${ }^{23}$. En 1998 se aprobaba el Estatuto de Roma de la Corte Penal Internacional permanente con sede en la Haya, con competencia para juzgar los crímenes de guerra, contra la humanidad, de agresión y genocidio.

Los Tribunales Penales Internacionales han adoptado importantes medidas en el ámbito de sus competencias para incluir la violencia sexual y los atentados contra la libertad sexual entre los crímenes de guerra y contra la humanidad, y han encausado y condenado a los autores de estos delitos.

El Estatuto del Tribunal Penal Internacional para la ex Yugoslavia, reconoce y tipifica la violación como crimen contra la humanidad ${ }^{24}$. Como resultado, en 1998 Hazim Delic, guardia de un campo de prisioneros serbio, fue condenado por delito de tortura por violar repetidamente a una prisionera, y en febrero de 2001, el Tribunal dictaba la primera sentencia de condena por violación como crimen contra la humanidad (Goldenberg Goldstoff, 2010: 500-501).

Por su parte, el Tribunal Penal Internacional de Ruanda ha incluido, por primera vez, la violación entre los crímenes constitutivos de genocidio y ha dictado sentencia condenatoria por la perpetración de este tipo de delitos ${ }^{25}$.

Siguiendo la trayectoria de los Tribunales Penales Internacionales constituidos ad hoc para juzgar los crímenes cometidos en la ex Yugoslavia y en Ruanda, el Estatuto de Roma de la Corte Penal Internacional permanente ha dado pasos más adelante al

\footnotetext{
${ }^{22}$ Asamblea General de las Naciones Unidas, “Agresión y violación de mujeres en el territorio de la ex Yugoslavia" (Naciones Unidas, 1996).

${ }^{23}$ Véanse las páginas web oficiales del Tribunal Penal Internacional para la ex Yugoslavia (ICTI, 2011) y del Tribunal Penal Internacional de Ruanda (ICTR, 2011).

${ }^{24}$ Updated statute of the International Criminal Court for the former Yugoslavia, artículo 5 (Naciones Unidas, 2009).

${ }^{25}$ (Goldenberg Goldstoff, 2010: 501); Naciones Unidas, "Prevención del genocidio" (Enseñanzas extraídas de Rwanda, 2011).
} 
tipificar la violencia sexual como un crimen individual e independiente, contra la humanidad y de guerra ${ }^{26}$.

Desde su creación, la Corte Penal Internacional se encuentra investigando violaciones del derecho internacional humanitario en tres estados signatarios, Uganda, la República Democrática del Congo y la República Central Africana, así como en Darfur, Sudán, estado no signatario. En marzo de 2010, iniciaba una investigación sobre las matanzas en Kenia, y el 3 de marzo de 2011, el Fiscal de la Corte Penal Internacional admitió la petición del Consejo de Seguridad de las Naciones Unidas y se encuentra investigando la situación en Libia $^{27}$.

A pesar de los avances que los Tribunales Penales Internacionales representan en la persecución, enjuiciamiento y condena de los criminales de guerra y contra la humanidad y también en la lucha contra la impunidad de la violencia sexual hacia las mujeres en los conflictos armados, en 2010, la representante de las Naciones Unidas en la República Democrático del Congo informaba de que entre julio y agosto más de 3000 mujeres habían sido brutalmente violadas por las Fuerzas Democráticas para la Liberación de Ruanda (Euronews, 15-10-2010). Según las Naciones Unidas, en el año 2009, 17.000 mujeres habían sido brutalmente violadas en este país, un 12\% más que el año anterior (elPeriódico.com, 18-10-2010). Queda la esperanza, pues, de que estos crímenes no queden impunes y sean juzgados ante la Corte Penal Internacional.

Violaciones masivas se han producido asimismo en Darfur, Sudán, y siguen amenazando a miles de mujeres en zonas en conflicto, post-conflicto y en los campos de refugiados. A pesar de los avances de la justicia internacional, y la visibilidad que ha adquirido este problema ante la opinión pública, la violencia sexual no ha cesado de emplearse con inaceptable frecuencia en los conflictos armados contemporáneos. Los

\footnotetext{
${ }^{26}$ El artículo 7 del Estatuto de Roma de la Corte Penal Internacional tipifica como crimen de lesa humanidad los actos de violación, esclavitud sexual, prostitución forzada, embarazo forzado, esterilización forzada o cualquier otra forma de violencia sexual de gravedad comparable, cometidos como parte de un ataque generalizado o sistemático contra la población civil y con conocimiento de dicho ataque. Asimismo, los "embarazos forzados", entendidos como confinamiento ilícito de una mujer a la que se ha dejado embarazada por la fuerza, con la intención de modificar la composición étnica de una población o de cometer otras violaciones graves del derecho internacional, son enjuiciados como crímenes contra la humanidad. Junto a ello, el artículo 8 tipifica los actos de violación, esclavitud sexual, prostitución forzada, embarazo forzado, definidos en el apartado f) del párrafo 2 del artículo 7, esterilización forzada y cualquier otra forma de violencia sexual que también constituyan una infracción grave de los Convenios de Ginebra, como crimen de guerra. Véase el Estatuto de Roma de la Corte Penal Internacional, adoptado por la Asamblea General de las Naciones Unidas el 17 de julio de 1998, en vigor el 1 de julio de 2002, de acuerdo con el artículo 126 (ICC, 1998).

${ }^{27}$ Véase la página oficial de la Corte Penal Internacional (ICC, 2011).
} 
tribunales militares procesan y juzgan los actos cometidos, y en numerosas ocasiones los encausados resultan absueltos por falta de pruebas y evidencias ${ }^{28}$. Aunque la Corte Penal Internacional evita los inconvenientes de los Tribunales Internacionales ad hoc, no todos los estados han ratificado aún el Estatuto de Roma de 1998.

La comunidad internacional ha reforzado, en los últimos años, su compromiso para hacer frente a la violencia sexual y para destacar el papel de las mujeres en las guerras. En el año 2000, era aprobaba la primera Resolución del Consejo de Seguridad de las Naciones Unidas, Resolución 1325 (2000), que aborda explícitamente el impacto de la guerra en las mujeres y destaca, asimismo, su contribución en la promoción de la paz.

La Resolución llama a las partes en conflicto a tomar medidas especiales y urgentes para proteger a las mujeres y a las niñas de la violencia sexual, y enfatiza la responsabilidad de los estados para evitar que estos crímenes queden impunes, excluyendo, cuando sea posible, los crímenes de guerra, contra la humanidad y de genocidio de las leyes de amnistía ${ }^{29}$.

Junto a ello, urge a los estados y a la comunidad internacional a promover la presencia de las mujeres en los procesos de toma de decisiones, en todos los niveles, como paso decisivo para lograr y mantener la paz de las regiones ${ }^{30}$. Consciente de que miembros de las propias fuerzas de seguridad y pacificación de las Naciones Unidas han sido juzgados y condenados por violación y delitos sexuales, el Consejo de Seguridad urge, en la Resolución 1325 (2000), a las propia Organización de las Naciones Unidas a incluir a mujeres en sus órganos de decisión, así como en sus fuerzas de pacificación y entre el personal humanitario ${ }^{31}$.

En este sentido, la Resolución destaca que la inclusión de la perspectiva de género en las acciones de los organismos internacionales, incluidas las fuerzas de pacificación, es necesaria para hacer frente a la violencia sexual en los conflictos y para atender adecuadamente a las mujeres desplazas y refugiadas, así como a las víctimas de las violaciones ${ }^{32}$.

Asimismo, en el año 2008 el Consejo de Seguridad aprobaba una nueva Resolución 1820 (2008), poniendo de relieve que la violencia sexual contra los niños y

\footnotetext{
${ }^{28}$ Sobre los límites de la Corte Penal Internacional para investigar y juzgar los delitos de violación véase Goldenberg Goldstoff (2010: 502, 506).

${ }^{29}$ Resolución 1325 (2000), adoptada por el Consejo de Seguridad de las Naciones Unidas, puntos 10 y 11 (Consejo de Seguridad de las Naciones Unidas, 2000).

${ }^{30}$ Resolución 1325 (2000), adoptada por el Consejo de Seguridad de las Naciones Unidas, puntos 10 y 11 (Consejo de Seguridad de las Naciones Unidas, 2000), puntos 1-7.

${ }^{31}$ Ibíd. Nota 29.

${ }^{32}$ Ibíd. Nota 29, punto 8.
} 
mujeres atrapados en zonas de conflicto, no sólo continúa, sino que es una práctica extendida y sistemática en los conflictos, hasta "alcanzar niveles alarmantes de brutalidad"33.

La nueva Resolución reconoce que la violencia sexual, empleada como arma de guerra deliberada contra la población civil, puede exacerbar significativamente los conflictos e impedir la restauración de la paz y la seguridad ${ }^{34}$. Asimismo, urge a los Estados, agencias internacionales, regionales, financieras y no gubernamentales a emprender acciones y actividades para asistir a las víctimas de la violencia sexual y a preparar al personal de seguridad, jurídico y sanitario para detectar y asistir a las víctimas ${ }^{35}$.

Demanda la aludida Resolución el cese inmediato y completo de todos los actos de violencia contra civiles por parte de todos los implicados en conflicto armado, con efecto inmediato, así como que dichas partes en conflicto tomen inmediatamente medidas eficaces para proteger a los civiles de cualquier forma de violencia sexual ${ }^{36}$.

Recuerda que la violación y otras formas de violencia sexual pueden ser constitutivas de crímenes contra la humanidad, crímenes de guerra, y de actos de genocidio, e insiste de nuevo en la necesidad de excluir dichos crímenes de las leyes de amnistía. Insta a los estados a cumplir sus obligaciones para enjuiciar a las personas responsables de dichos actos, y para garantizar la igual protección de las mujeres y las niñas bajo la ley ${ }^{37}$.

Una vez más, la Resolución citada, insta a la comunidad internacional y a los Estados, a promover la presencia de las mujeres en los procesos de toma de decisión y en las negociaciones de paz $^{38}$. En este sentido, destaca la labor de la unidad policial compuesta exclusivamente por mujeres de la India, dentro de la Misión de las Naciones Unidas en Liberia (UNMIL) (Carvajal, 2010).

Junto a ello, las Naciones Unidas han creado una iniciativa inter-sectorial, “Acción de las Naciones Unidas contra la Violencia Sexual en zonas en Conflicto”, para llamar la atención sobre este tipo de agresiones en las zonas en conflicto y ponerles fin.

A nivel internacional, la Resolución 1820 (2008) es significativa porque el Consejo de Seguridad reconoce que la violencia sexual sistemática y generalizada

\footnotetext{
33 "Security Council demands immediate and complete halt to acts of sexual violence against civilians in conflicts zones, unanimously adopting Resolution 1820 (2008)" (Consejo de Seguridad de las Naciones Unidas, 2008).

${ }^{34}$ Ibíd. Nota 32, punto 1.

${ }^{35}$ Ibíd. Nota 32, puntos 13 y 14.

${ }^{36}$ Ibíd. Nota 32, puntos 2 y 3.

${ }^{37}$ Ibíd. Nota 32, punto 4.

38 "Security Council demands immediate and complete halt to acts of sexual violence against civilians in conflicts zones, unanimously adopting Resolution 1820 (2008)" (Consejo de Seguridad de las Naciones Unidas, 2008), punto 12.
} 
contra civiles es una amenaza contra la paz y la seguridad y, por tanto, que es de su competencia. Esto implica que el Consejo de Seguridad puede imponer sanciones a los estados que la incumplan o que no toman medidas para abordar el problema, y que el propio Consejo asume su responsabilidad (Henckaerts, 2008).

No obstante, aunque aplaudida por parte de las asociaciones de mujeres y activistas, la Resolución reviste algunas limitaciones. A juicio de Melissa Goldenberg, ésta incurre en inconsistencias y puede llegar a poner en evidencia a la Resolución 1325 (2000), que exige a las partes en conflicto respetar los derechos de las mujeres y promover su participación en los procesos de negociaciones y participación para la paz (Goldenberg Goldstof, 2010: 493). Asimismo, la Resolución requiere mayores esfuerzos e instrumentos para su implementación y para que los criminales sean juzgados (Op. cit., pg 516). En definitiva, si los estados no prosiguen en la adopción de las medidas pertinentes, las violaciones y demás delitos contra la libertad sexual continuarán existiendo en los conflictos contemporáneos, con el riesgo de que, con frecuencia, resulten impunes.

\section{Conclusión: la igualdad entre los sexos, el desarrollo y la paz}

Como hemos visto, los movimientos feministas y la presión de las mujeres han hecho posible que la comunidad internacional haya dado importantes pasos en las últimas décadas del siglo XX para promover el avance de las mujeres en todas las regiones.

La igualdad entre los sexos y el avance de las mujeres son elementos inseparables del desarrollo, la seguridad y la paz. Aquellos países y comunidades en las que las mujeres viven oprimidas, no tienen acceso al desarrollo, a la educación, a los recursos, y encuentran obstáculos formales e informales para participar en la vida económica, política y social, están condenadas al estancamiento y la pobreza ${ }^{39}$. De las mujeres depende, en buena medida, la nutrición, educación y desarrollo de la familia y los hijos. Son, asimismo, un sostén fundamental de las comunidades y países. La convivencia en la igualdad genera, a su vez, una espiral de virtudes y hábitos sociales saludables.

\footnotetext{
39 Véanse los informes del Foro Económico Mundial, que insisten en la relación entre el desarrollo y la igualdad entre los sexos: The global gender gap. Report 2007 (WEFORUM 2007); The global gender gap. Report 2010 (WEFORUM, 2010); "Investing in girls, investing in development - The girl effect" (WEFORUM, 2009).
} 
Por todas estas razones, el avance de la condición de las mujeres en la sociedad, y su igualdad jurídica, son parte de la campaña internacional para prevenir la violencia sexual y la violación en los conflictos. Cada vez más mujeres se incorporan a los ejércitos y a las fuerzas nacionales e internacionales de seguridad y pacificación. Éstas no son sólo elementos pasivos, sino que tienen un papel activo y relevante que jugar en el mantenimiento de la seguridad y la paz de las regiones del mundo.

Aunque se han dado importantes pasos para definir la violencia sexual como crimen de guerra, contra la humanidad y como acto constitutivo del crimen de genocidio, aún son necesarios más esfuerzos para reforzar la conciencia igualitaria, incluir la perspectiva de género en las distintas instancias internacionales y nacionales, y también en los tribunales que juzgan los crímenes contra el derecho internacional humanitario.

En los temas que hemos tratado en las líneas precedentes sobre violaciones de derechos humanos y delitos contra la libertad sexual, padecidos fundamentalmente por las mujeres en los conflictos armados de todos los tiempos, incluidos los contemporáneos, la participación abundante de éstas en la apreciación y enjuiciamiento de dichas cuestiones y su presencia entre los magistrados, en las fuerzas de pacificación, y en las instancias para la represión de estos crímenes parecería lógica. Sin embargo, en los procesos de negociación de paz que han tenido lugar en los últimos años, las mujeres han constituido sólo el 8 por ciento de los participantes, menos del 3 por ciento de los firmantes, y ninguna mujer ha sido elegida jefa mediadora en los diálogos para la paz liderados por las Naciones Unidas (UN Women, 2011). 


\section{BIBLIOGRAFÍA}

- Bennhold, Katrin (2010): "Waging war and peace with women". En The New York Times, 02-11-2010 [en línea], Disponible en: http://www.nytimes.com/2010/11/03/ world/europe/03iht-letter.html?_r=1\&ref=thefemalefactor [7-02-2011].

- Bartley, Paula (2003): Votes for women 1860-1928. Londres: Hodder y Stoughton.

- Carvajal, Doreen (2010): “A female approach to peace keeping”. En The New York Times, 05-02-2010 [en línea], Disponible en: http://www.nytimes.com/2010/03/06/ world/africa/06iht-ffpeace.html?ref=thefemalefactor [07-02-2011].

- CICR - Comité Internacional de la Cruz Roja (2007): “¿Las mujeres en la guerra son particularmente vulnerables?" [en línea] Disponible en: http://www.icrc.org/web/spa/sitespa0.nsf/html/women-vulnerability-010307 [07-02-2011].

- Consejo de Seguridad de las Naciones Unidas (2000): "Resolution 1325 (2000). Adopted by the Security Council at its 4213th meeting, on 31 October 2000" [en línea] Disponible en: http://www.un.org/events/res_1325e.pdf [03-02-2011].

. (2008):" Security Council demands immediate and complete halt to acts of

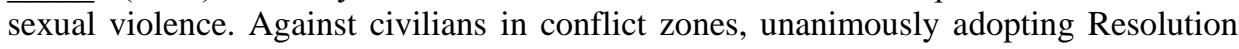
1820 (2008)" [en línea] Disponible en: http://www.un.org/News/Press/docs/2008/ sc9364.doc.htm [03-02-2011].

- elPeriódico.com (2010): "Protestas de Mujeres por las violaciones en el Congo" 18 de octubre [en línea] Disponible en: http://www.elperiodico.com/es/noticias/internacional/ 20101018/protesta-mujeres-por-las-violaciones-congo/540104.shtml [07-02-2011].

- Euronews (2010): "Violaciones en el Congo. El horror se repite, según la representante de la ONU" [en línea] 15 de octubre, Disponible en: http://es.euronews.net/2010/ 10/15/violaciones-en-el-congo-el-horror-se-repite-segun-la-representante-de-la-onu/ [07-02-2011].

- Friedan, Betty (1992): The feminine mystique. $1^{\mathrm{a}}$ ed. 1963. Londres: Penguin Books.

- Geneva Conventions (2008) [en línea] Disponibles en: http://www.icrc.org/eng/war-andlaw/treaties-customary-law/geneva-conventions/index.jsp [02-02-2011].

- Goldenberg Goldstof, M. (2010): "Security Council Resolution 1820: An imperfect but necessary resolution to protect civilians from rape in war zones". En Cardozo Journal of Law \& Gender, vol. 16: 491, pp. 491-517 [en línea] Disponible en: http://cardozolawandgender.com/uploads/2/7/7/6/2776881/16-3_goldstoff.pdf [02-02-2011].

- Henckaerts, J. M. (2008): "La violencia sexual como método de guerra", entrevista con el Comité Internacional de la Cruz Roja, 30-06-2008 [en línea] Disponible en: http://www.icrc.org/WEB/SPA/sitespa0.nsf/html/sexual-violence-interview-260608 [12-02-2011]. 
- ICC - International Criminal Court (1998): "Estatuto de Roma de la Corte Penal Internacional" [en línea] Disponible en: http://www.icc-cpi.int/NR/rdonlyres/ADD 16852AEE9-4757-ABE7-9CDC7CF02886/140177/Rome_Statute_Spanish.pdf [07-02-2011].

- (2011): "Situations and Cases" [en línea] Disponible en: http://www.icccpi.int/Menus/ICC/Situations+and+Cases/ [07-02-2011].

- ICTI - International Criminal Tribunal for the former Yuguslavia (2011) [en línea] Disponible en: http://www.icty.org/sections/AbouttheICTY [07-02-2011].

- ICTR - International Criminal Tribunal for Rwanda (2011) [en línea] Disponible en: http://www.unictr.org/ [07-02-2011].

- IHL - International Humanitarian Law (1899): “Convention (II) with Respect to the Laws and Customs of War on Land and its annex: Regulations concerning the Laws and Customs of War on Land. The Hague, 29 July 1899" [en línea] Disponible en http://www.icrc.org/ihl.nsf/FULL/150?OpenDocument [02-02-2011].

- (1899a): Convention (III) for the Adaptation to Maritime Warfare of the Principles of the Geneva Convention of 22 August 1864", The Hague, 29 July 1899 [en línea] Disponible en http://www.icrc.org/ihl.nsf/FULL/ 155?OpenDocument [02-022011].

. (1907): "Convention (IV) respecting the Laws and Customs of War on Land and its annex: Regulations concerning the Laws and Customs of War on Land", The Hague, 18 October 1907 [en línea] Disponible en http://www.icrc.org/ihl.nsf/FULL/195 [02-02-2011].

- (1949): "Convention (III) relative to the Treatment of Prisoners of War", Geneva, 12 August 1949 [en línea] Disponible en: http://www.icrc.org/ihl.nsf/INTRO/375?OpenDocument [02-02-2011].

- (1949a): "Convention (IV) relative to the Protection of Civilian Persons in Time of War", Geneva, 12 August 1949 [en línea] Disponible en: http://www.icrc.org/ihl.nsf/FULL/380?OpenDocument [02-02-2011].

- Lindsey, C. (2000): "Las mujeres y la guerra". En Revista Internacional de la Cruz Roja, num. 839, pp. 561-580 [en línea] Disponible en: http://www.icrc.org/web/ spa/sitespa0.nsf/html/5TDP9Q\#1 [07-02-2011].

Naciones Unidas (1985): "Report of the world conference to review and appraise the achievements of the United Nations decade for women: Equality development and peace". Nairobi, 15-26 July 1985 [en línea] Disponible en: http://www.un.org/ womenwatch/daw/beijing/otherconferences/Nairobi/Nairobi\%20Full\%20Optimized.pdf [02-02-2011].

- (1993): "Declaración sobre la eliminación de la violencia contra la mujer. Resolución de la Asamblea General - A/RES/48/104 del 20 de diciembre de 1992" [en línea] Disponible en: http://www.acnur.org/biblioteca/pdf/1286.pdf [03-02-2011]. 
- Naciones Unidas (1995): "Fourth World Conference on Women. Platform for action" [en línea] Disponible en: http://www.un.org/womenwatch/daw/beijing/platform/ [02-02-2011].

- (1996): "Resolución aprobada por la Asamblea General: sobre la base del informe de la Tercera Comisión (A/50/635/Add.3). Agresión y violación de mujeres en el territorio de la ex Yugoslavia - A/RES/50/192, de 23 de febrero de 1996" [en línea] Disponible en: http://www.unhchr.ch/Huridocda/Huridoca.nsf/0/d41657867 1a9b40b8025666d00594847?Opendocument [04-02-2011].

. (2000): "Las cuatro conferencias mundiales sobre la mujer, 1975-1995. Una perspectiva histórica - Período extraordinario de sesiones de la Asamblea General de las Naciones Unidas para examinar la Plataforma de Acción de Beijing”, Nueva York, 5 a 9 de junio de 2000 [en línea] Disponible en: http://www.un.org/ spanish/conferences/Beijing/Mujer2011.htm [07-02-2011].

- (2009): "Updated statute of the International Criminal Court for the former Yugoslavia”, [en línea] Disponible en: http://www.icty.org/x/file/Legal\%20Library/ Statute/statute_sept09_en.pdf [07-02-2011].

. (2011): Enseñanzas extraídas de Rwanda. Las Naciones Unidas y la prevención del Genocidio - "Prevención del genocidio" [en línea] Disponible en: http://www.un.org/spanish/preventgenocide/rwanda/infokit.shtml [07-02-2011].

- OACDH - Oficina del Alto Comisionado de las Naciones Unidas para los Derechos Humanos (1979): "Convención sobre la eliminación de todas las formas de discriminación contra la mujer”, CEDAW, Naciones Unidas [en línea] Disponible en: http://www2.ohchr.org/spanish/law/cedaw.htm [03-02-2011].

- UNIFEM - Fondo de las Naciones Unidas para las Mujeres (2011) [en línea] Disponible en: http://www.unifem.org/gender_issues/women_war_peace [02-02-2011].

- UN Women (2011), United Nations [en línea] Disponible en: http://www.unifem.org/ gender_issues/women_war_peace/ [12-02-2011].

- WEFORUM - World Economic Forum (2007): “The global gender gap. Report 2007”, Ginebra [en línea] Disponibles en: https://members.weforum.org/pdf/gendergap/ report2007.pdf [12-02-2011].

. (2009): "Investing in girls, investing in development - The girl effect" [en línea] Disponible en: http://www.weforum.org/ women-leaders-and-gender-parity [1202-2011].

. (2010): “The global gender gap. Report 2010”, Ginebra [en línea] Disponible en: http://www.weforum.org/en/Communities/Women\%20Leaders\%20and\%20Gender\%20Pari ty/GenderGapNetwork/index.htm [12-02-2011]. 